\title{
Coeliac Disease - New Pathophysiological Findings and Their Implications for Therapy
}

\author{
Jürgen Stein ${ }^{a, b} \quad$ Detlef Schuppan ${ }^{c, d}$ \\ ${ }^{a}$ Department of Gastroenterology and Clinical Nutrition, Sachsenhausen Hospital, Teaching Hospital of the Goethe University Frankfurt, \\ ${ }^{\mathrm{b}}$ Interdisciplinary Crohn Colitis Centre Rhein-Main, Frankfurt/M., \\ ${ }^{c}$ Institute of Translational Immunology, University Medical Center, Hospital Mainz, Germany \\ ${ }^{\mathrm{d}}$ Division of Gastroenterology, Beth Israel deaconess Medical Center, Harvard Medical School, Boston, MA, USA
}

\section{Keywords}

Coeliac disease - Gluten-sensitive enteropathy ·

Malabsorption - Zonulin inhibitor - Therapeutic vaccine .

Transglutaminase inhibitors

\section{Summary}

Coeliac disease (CD) is one of the most common diseases worldwide, resulting from a combination of environmental (gluten) and genetic (human leucocyte antigen (HLA) and non-HLA genes) factors. Depending on the geographical location, the prevalence of CD has been estimated to approximate $0.5-1 \%$. The only treatment currently available for CD is a gluten-free diet (GFD) excluding gluten-containing cereals such as wheat, rye, and barley, and other foodstuffs with natural or added gluten. However, adherence rates and patient acceptance are often poor. Moreover, even in fully adherent patients, the diet may fail to induce clinical or histological improvement. Hence, it is unsurprising that studies show CD patients to be highly interested in non-dietary alternatives. The following review focuses on current pathophysiological concepts of $C D$, spotlighting those pathways which may serve as new possible, non-dietary therapeutic targets in the treatment of CD.

\section{Schlüsselwörter}

Zöliakie · Glutensensitive Enteropathie ·

Malabsorption - Zonulin-Inhibitor .

Therapeutischer Impfstoff - Transglutaminase-Inhibitoren

\section{Zusammenfassung}

Die Zöliakie ist weltweit eine der häufigsten Erkrankungen, die aus einer Kombination von Umwelt- (Gluten) und genetischen (humanes Leukozyten-Antigen (HLA) und Nicht-HLA-Gene) Faktoren resultiert. Abhängig von der geographischen Lage, wird die Prävalenz der Zöliakie auf etwa 0,5-1\% der Bevölkerung geschätzt. Die einzige Behandlung, die derzeit bei Zöliakie verfügbar ist, besteht in einer glutenfreien Diät (GFD), die glutenhaltige Getreide wie Weizen, Roggen und Gerste sowie andere Lebensmittel mit natürlichem oder zugesetztem Gluten ausschließt. Die Complianceraten und die Akzeptanz durch die Patienten sind jedoch oft schlecht. Weiterhin kann die Diät selbst bei Patienten, die diese vollständig einhalten, möglicherweise nicht zu einer klinischen oder histologischen Verbesserung führen. Daher ist es nicht verwunderlich, dass Studien zeigen, dass ZöliakiePatienten sehr an nichtdiätetischen Alternativen interessiert sind. Die folgende Übersicht konzentriert sich auf aktuelle pathophysiologische Konzepte der Zöliakie, bei denen jene Signalwege herausgestellt werden, die als mögliche neue, nichtdiätetische therapeutische Ansatzpunkte in der Behandlung der Zöliakie dienen könnten.

\section{KARGER \\ Fax +497614520714 \\ Information@Karger.com}

www.karger.com (c) 2014 S. Karger GmbH, Freiburg

$1662-6664 / 14 / 0303-0156 \$ 39.50 / 0$

Accessible online at:

www.karger.com/vim
Prof. Dr. med. Dr. oec. troph. Jürgen Stein

Department of Gastroenterology and Clinical Nutrition

Krankenhaus Sachsenhausen

Teaching Hospital of the Goethe University Frankfurt

Schulstraße 31, 60594 Frankfurt, Germany

J.Stein@em.uni-frankfurt.de 


\section{Introduction}

Coeliac disease (CD) is defined as chronic small intestinal immune-mediated enteropathy elicited by gluten and related prolamines in genetically predisposed individuals [1], and characterised by the presence of a variable combination of gluten-dependent clinical manifestations, CD-specific antibodies, HLA(human leucocyte antigen)-DQ2 or HLA-DQ8 haplotypes; a characteristic histomorphological picture of the proximal small intestinal mucosa (inflammatory infiltrate, crypt hyperplasia, villous atrophy); and remission of clinical and serologic findings on keeping a gluten-free diet (GFD).

CD occurs in genetically susceptible populations in many regions worldwide, with a prevalence of $0.5-1 \%$ in Americans and Europeans, as well as in the populations of Australia, North Africa, the Middle East, India, and probably also northern China (depending on the prevalence of HLA-DQ2 and HLA-DQ8). In some populations, including those of Finland and Mexico, and among the Sahrawi children of North Africa, the prevalence lies between 2 and 5\% [2].

CD can manifest itself clinically at any age. The disease aetiology is multifactorial, with a strong genetic susceptibility, as documented in studies of twins and in studies demonstrating a strong dependence on HLA-DQ2 and HLA-DQ8 haplotypes [3].

The clinical manifestations of CD can vary considerably, from none at all (asymptomatic CD) to a wide spectrum of intestinal symptoms such as diarrhoea, steatorrhoea and malabsorption (classical CD), and atypical symptoms (e.g. neurologic findings including depression and gluten ataxia; reproductive disease, including abnormalities in menarche and menopause; and oral/cutaneous disease, including dermatitis herpetiformis). Refractory CD (RCD), based on the expression of a clonal TCR $-\gamma$ chain gene by intraepithelial lymphocytes (IELs) and divided into two types, RCD I and RCD II, is characterised by persistent or recurrent malabsorptive symptoms and signs with villous atrophy (VA) despite adherence to a strict GFD for more than 12 months (for review see [4-6]). While RCD I is associated with a slight increase of mortality, RCD II is a far more serious form of the disease, with a 5-year mortality rate of up to $50 \%$ following diagnosis. Patients with RCD II have also been shown to be at the highest risk of enteropathy-associated T cell lymphoma (EATL) $[7,8]$.

Although it is now some 60 years since Willem Dicke [9], a Dutch paediatrician, demonstrated a 'wheat factor' as the causative agent of $\mathrm{CD}$, a lifelong GFD remains to this day the only effective treatment [10]. While daily gluten consumption in the general population has been calculated to be approximately 15-20 g [11], several studies have demonstrated that daily doses of as little as $<1 \mathrm{~g}$ are sufficient to induce mucosal lesions in CD patients. For CD patients, $10-50 \mathrm{mg}$ gluten per day has been shown to be a safe threshold [12-14].

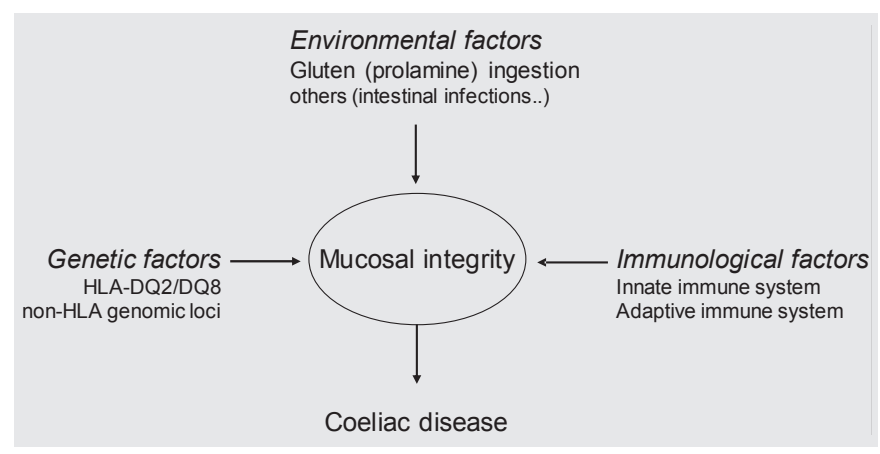

Fig. 1. The pathogenesis of $C D$ is multi-faceted, involving environmental (gluten, intestinal infections), genetic, and immunological factors.

Although more than $95 \%$ of patients with CD have an uncomplicated disease that resolves under a GFD, the adherence rates and patient acceptance vary $[15,16]$. Furthermore, even in fully adherent patients, the diet fails to induce clinical or histological improvement in $7-30 \%$ of the patients [17-19], and $2-5 \%$ of the patients develop RCD [20, 21].

Furthermore, while quality of life (QOL) has been shown to improve after diagnosis and subsequent to GFD introduction, some studies found reduced health-related QOL [22, 23]. CD patients on a GFD may also develop nutritional deficiencies $[24,25]$.

Unsurprisingly, a recent study demonstrated that a large proportion of patients with CD is dissatisfied with the GFD and therefore seeks therapeutic alternatives to it [26].

Based on an improved understanding of the pathogenic pathways underlying $\mathrm{CD}$, several types of therapeutic approach with the potential to augment or supplant the GFD have been generated. This article aims to review novel nondietary approaches based on new pathophysiological findings and their implications for therapy.

\section{Pathogenesis of Coeliac Disease}

The pathogenesis of $\mathrm{CD}$ is multifaceted, involving environmental (gluten, intestinal infections), genetic, and immunological factors (fig. 1).

\section{Environmental Factors - the Role of Dietary Proteins}

Proteins in the dietary cereal grains wheat, rye, and barley - collectively termed 'gluten' - are known to be the environmental factors which cause disease exacerbation. Strictly speaking, however, gluten is the scientific name only for wheat proteins, while the related proteins in barley and rye capable of activating CD are known as hordeins and secalins, respectively. Whereas wheat, rye, and barley have a common ancestral origin in the grass family, oats, which only rarely (if at all) trigger $\mathrm{CD}$, are more distantly related, thus lacking 


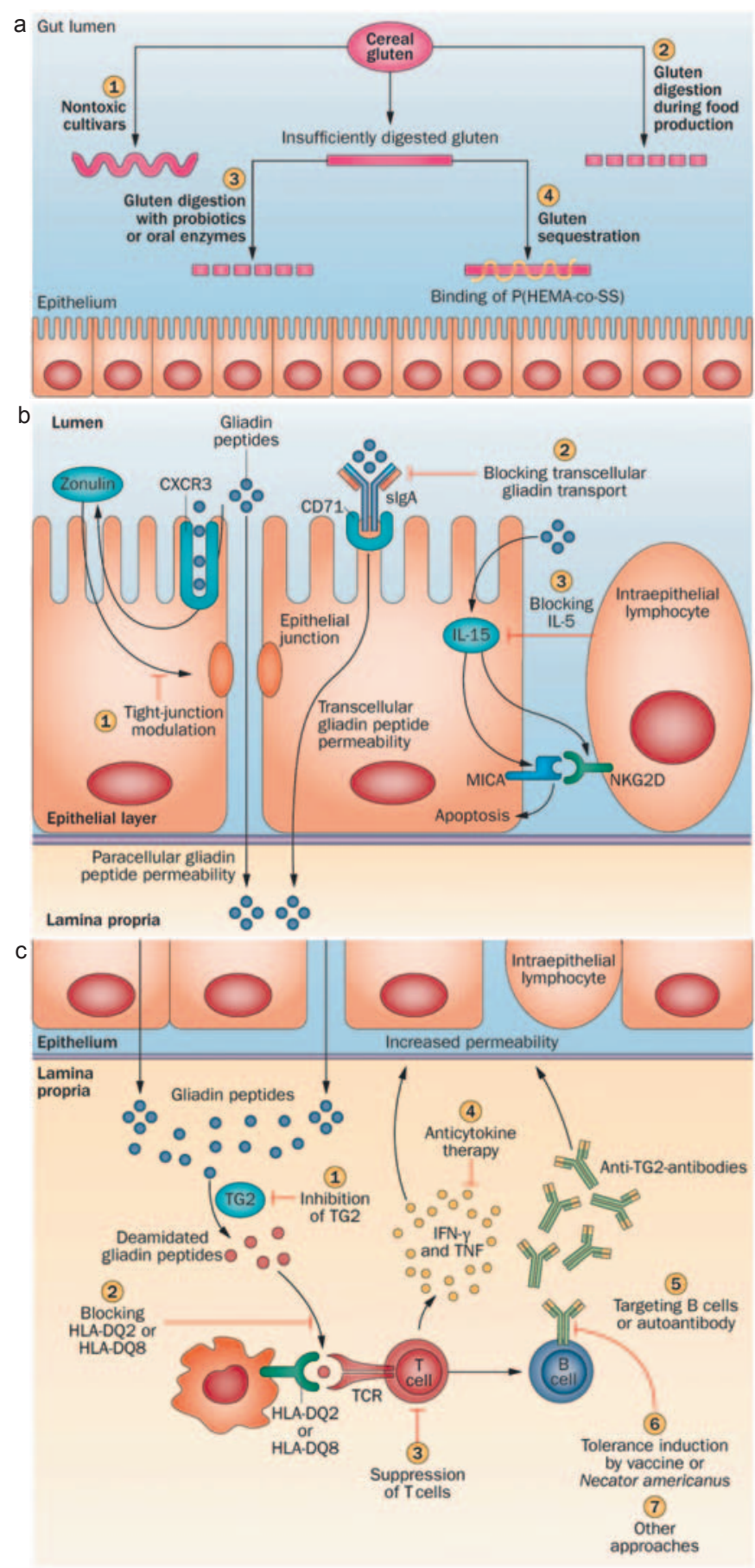

Fig. 2. Novel therapeutic approaches. a Therapeutic approaches acting in the lumen of the small intestine, either binding or degrading ingested gluten peptides in the intestine (glutenases, gluten binders, neutralising antibodies). b Suggested treatment options that prevent gluten-induced effects in the intestinal epithelium: Blocking the ZOT receptor with the octapeptide AT-1001 to decrease intestinal permeability is another option. Furthermore, since deamidation of gluten peptides by tTG2 and subsequent presentation by HLA-DQ2/8 initiates the adaptive immune responses, tTG2 inhibitors and DQ2-blocking peptides seem an attractive possibility to prevent inflammation. c Therapeutic options based on prevention of immunological cascades in cells of the lamina propria (especially in patients with RCD), either by lymphocyte blocking (anti-IL-15, anti-CCR9, anti- $\alpha 4,-\beta 7$ ) or by tolerance induction (reprinted by permission from Macmillan Publishers Ltd from [95]). many of the proteins found in wheat. In contrast, the proteins found in rice, maize, sorghum, and millet, which are even more distantly related, do not activate CD.

Gluten contains more than a hundred proteins, present either as monomers or as oligomers and polymers, and linked by interchain disulphide bonds characterised by high content of glutamine and proline (in the form of prolamines), and by low content of charged amino acids. Based on the availability of complete amino acid sequences, gluten can be divided into three broad groups: sulphur-rich (S-rich), sulphur-poor (Spoor), and high-molecular-weight (HMW) prolamines. Traditionally, gluten proteins have been classified according to their solubility in alcohol-water solutions (e.g. $60 \%$ ethanol) as soluble gliadins and insoluble glutenins. The alcohol-soluble gliadin fraction consists mainly of monomeric proteins, which either lack cysteine ( $\omega$-gliadins) or have only intrachain disulphide bonds ( $\alpha$-type and $\gamma$-type gliadins). $\omega$-gliadins are characterised by the highest content of glutamine, proline, and phenylalanine, accounting for around $80 \%$ of the total composition [27].

The exceptionally high glutamine and proline content in the gliadins and glutenins of wheat, and also in hordeins and secalins, plays a key role in the pathogenesis of CD:

i) Lacking sufficient prolyl endopeptidases in the human intestine, the high proline content renders these proteins relatively resistant to proteolytic digestion, resulting in the accumulation of relatively large toxic peptides (mainly 50 amino acids in length);

ii) Due to their high content of glutamine and hydrophobic amino acid residues, gluten proteins, especially the alcoholsoluble fraction (e.g. gliadins of wheat, secalins of barley, and hordeins of rye) but also the glutenins, are preferred substrates for the ubiquitous cellular enzyme tissue transglutaminase 2 (tTG2). TG2 can either crosslink certain glutamines in one protein chain with a lysine residue on another chain by forming a covalent isopeptide bond, or merely deamidate this glutamine to an acidic glutamic acid residue, which is of major importance for the pathogenesis of CD.

More than 50 distinct (deamidated) gluten peptides exerting cytotoxic, immunomodulatory, and gut-permeating activities have been described [28]. These activities have been partially mapped to specific domains in $\alpha$-gliadin (fig. 2): the cytotoxic peptides $31-43$ and $31-49$, the immunomodulatory peptide 57-89 (33-mer), the CXCR3-binding, zonulin-releasing (gut-permeating) peptides 111-130 and 151-170, and the interleukin(IL)-8-releasing peptide 261-277. The 33mer peptide from $\alpha 2$-gliadin, which contains 6 partly overlapping HLA-DQ2-binding amino acid sequences and is also regarded as a coeliac 'superantigen' [28, 29], has been shown to be resistant to degradation by gastrointestinal peptidases reaching the submucosal immune system in an intact peptide [30].

After reaching the lamina propria, either by epithelial transcytosis or through increased epithelial tight junctional 
Fig. 3. Posttranslational modification of gluten peptides. a, b Gluten peptides that are highly resistant to intestinal proteases reach the lamina propria, either via epithelial transcytosis or due to increased epithelial tight junctional permeability. Here, they are deamidated through the activity of tissue tTG2(transglutaminase 2)-generating peptides with negatively charged amino acid residues that bind with higher affinity to the disease-associated HLADQ2 or HLA-DQ8 molecules. P4, P6, and P7 pockets in HLA-DQ2 and $\mathrm{P} 1$ and $\mathrm{P} 9$ pockets in HLA-DQ8 have a preference for negatively charged anchor residues (modified from [3]). b
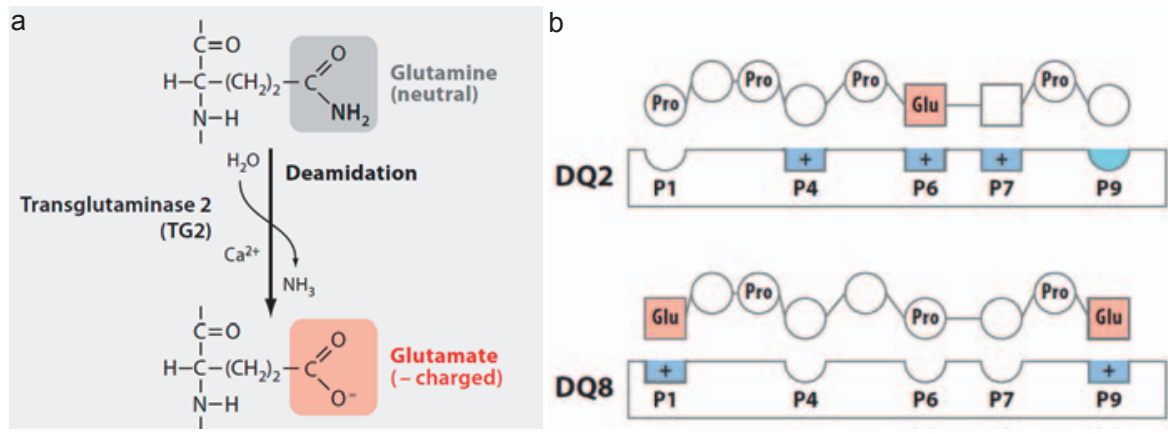

permeability, gluten peptides are deamidated through the activity of tTG2, and (except the 33mer peptide, which does not need further processing) [31,32] presented in the lamina propria by dendritic cells to activate $\mathrm{CD}^{+} \mathrm{T}$ cells $[3,33]$.

In contrast, the cytotoxic $\alpha$-gliadin peptides $\mathrm{p} 31-49$ and p31-49, which are thought not to bind to HLA-DQ2 and -DQ8, have been shown to upregulate IL-15 production in epithelial cells, macrophages, and dendritic cells, thus increasing IEL infiltration and epithelial cell apoptosis via NKGD2D und MICA receptors, respectively cumulating in cytotoxic damage to the epithelium [29, 33, 34].

\section{Genetic Factors}

Evidence for genetically-based susceptibility for CD has been gained from epidemiological studies showing that up to $20 \%$ of first-degree kin are equally affected by CD, with concordance rates $>75 \%$ in monozygotic twins [3, 35]. The leucocyte antigen (HLA) class II genes HLA-DQ2 and -DQ8 have been demonstrated to be the strongest genetic susceptibility factors by far: Whereas more than $95 \%$ of CD patients carry HLA-DQ2 and -DQ8, these genes are found in only $25-30 \%$ of the Caucasian population, of whom only $4 \%$ develop CD, indicating that additional factors also play a role. Using genome-wide association study (GWAS), at least 115 genes harbouring non-HLA susceptibility factors associated with $\mathrm{CD}$ have been described, of which 28 have been shown to be immune-related $[3,36]$. However, these genes do not contribute more than $4-5 \%$ to the overall genetic risk, which is dominated by HLA-DQ2 or -DQ8.

\section{Immunological Factors}

HLA-DQ2 and -DQ8 play a plausible key role in CD due to their unique ability to bind the proline-rich gluten peptides, especially those with a negative charge due to TG2mediated deamidation, resulting in a more rigorous $\mathrm{CD}+$ Th1 T cell activation. Both HLA-DQ2 and -DQ8, such as the lysine positioned at $\beta 71$ and at positions $\mathrm{P} 4, \mathrm{P} 6$, and $\mathrm{P} 7$ of DQ2, contain positively-charged pockets which promote the binding of negatively-charged glutamic acid residues generated by the autoantigen TG2 (fig. 3) [3, 29].

Gluten-responsive activated $\mathrm{T}$ cells produce proinflammatory cytokines, predominantly interferon- $\gamma$ (IFN- $\gamma$ ). IFN- $\gamma$ activates macrophages, which in turn secrete tumour necrosis factor $\alpha$ (TNF- $\alpha)$ and proteolytic matrix metalloproteinases (MMPs). Both cytokines trigger the expression of proteolytic MMPs in intestinal myofibroblasts, resulting in matrix proteolysis alteration, which in turn leads to mucosal injury and villous atrophy. In addition, via a phosphatidylinositol-3-kinase-dependent pathway and mediated by thioredoxin (TRX), IFN- $\gamma$ triggers the activation of tTG2, thereby establishing an autoamplificatory loop for gluten-induced inflammation [37]. In duodenal biopsies of CD patients, neutralisation of IFN- $\gamma$ has been shown to ameliorate gluten-induced mucosal damage [38].

Chronic exposure of CD patients to dietary gluten is invariably accompanied by the production of autoantibodies against tTG2. Anti-tTG2 antibodies are preferentially localised in the subepithelial layer, where they adhere to extracellular tTG2 on fibroblasts and on the basement membrane of the small intestine. Anti-tTG2 have been shown to induce enterocyte proliferation and inhibit enterocyte differentiation, and are able to modulate epithelial barrier function, thereby promoting intestinal crypt hyperplasia and villous blunting (reviewed in [37]).

\section{Non-Dietary Therapies of Coeliac Disease}

As already mentioned, a lifelong GFD is not only burdensome, but difficult to maintain and frequently unsuccessful. Thus, there is a need for effective, inexpensive, and safe alternative treatment options for $\mathrm{CD}$ and new approaches in adjunctive therapy. Although, at the present time, it is unrealistic for such novel therapies to counteract effects of gluten at the levels typically contained in the Western diet (15-20 g daily), their initial aim should be to neutralise at least small 
amounts of up to $3 \mathrm{~g}$ gluten per day. Since few therapeutic alternatives are currently available to treat RCD, more costly compounds with less favourable side-effect profiles may be acceptable in these patients. In the second part of this paper, we discuss new treatment strategies for the future which have shown potential in early studies in $\mathrm{CD}$, with encouraging results in vivo and in vitro.

Novel non-dietary treatment options can be classified by their targets during different phases in the pathogenesis of $\mathrm{CD}$ (e.g. candidates targeting the disease-inducing prolamines, endogenous molecules involved in the pathogenesis) or by their ability to induce tolerance to gluten (fig. 2).

\section{Targeting Disease-Inducing Gluten and Other Prolamines}

\section{Preventing Intestinal Gluten (Prolamine) Absorption}

Another strategy to prevent the interaction of immunogenic gluten peptides with submucosal immune cells is the use of HMW polymers to selectively bind gluten, thereby preventing its breakdown and absorption [39].

Poly(hydroxyethylmethacrylate-co-styrene sulfonate ( $\mathrm{P}($ HEMA-co-SS $))$ is a synthetic polymeric compound that sequesters food-derived gluten in the gastrointestinal lumen by forming high-affinity complexes with $\alpha$-gliadin, thus preventing enzymatic digestion of gluten and other prolamines into smaller, medium-length immunogenic peptides [39, 40].

In a first preclinical study, Pinier et al. [41] assessed the capacity of P(HEMA-co-SS), a copolymer of hydroxyethyl methacrylate and styrene sulfonate, to reduce paracellular permeability, and demonstrated its ability to normalise antigliadin immunoglobulin $\mathrm{A}$ in intestinal washes and reduce gliadin-invoked TNF- $\alpha$ secretion in duodenal biopsies of CD patients.

\section{Oral Enzyme Therapy}

Because the human digestive tract has an insufficient supply of prolyl endopeptidases (PEPs), the enzymes capable of hydrolysing the immunogenic proline-rich peptides found in gluten and related prolamines, oral PEP therapy may offer another strategy to reduce the amounts of immunogenic gluten peptides reaching the small intestine. This approach is analogous to exogenous lactase supplementation in the treatment of lactose intolerance. Enzymatically active PEPs are expressed in several microbial species, including Aspergillus niger, Sphingomonas capsulata, Flavobacterium meningosepticum, and Myxococcus [42].

A. niger PEP (AN-PEP) is enzymatically active in a $\mathrm{pH}$ ranging from 2 to 8 , and is therefore active both in the stomach and in the intestine. It has also been shown to be resistant to gastric pepsin. In vitro, AN-PEP is able to break down gluten and gluten peptides into non-immunogenic fragments within a few minutes [43, 44]. A recent pilot study of 16 subjects demonstrated AN-PEP to be well-tolerated, but no efficacy data have been presented [45].

PEPs derived from F. meningosepticum (PEP-FM) have been shown to effectively reduce levels of the immunogenic 33 mer in vitro and in vivo in rats. However, subsequent studies revealed that large quantities of the enzyme would be required to detoxify a normal daily gluten intake, and that PEPFM activity decreased due to its instability in the presence of gastric enzymes [42, 46].

To enhance gluten degradation, combinations of complementary peptides have been introduced [47]. ALV003 is composed of two gluten-specific proteases: a modified recombinant version of a Hordeum vulgare (barley) cysteine endoprotease (EP-B2) and a modified recombinant version of a $S$. capsulata prolyl endopeptidase.

In a phase IIb trial involving 41 patients with stable $\mathrm{CD}$, in which individuals were randomised to receive oral ALV003 or placebo daily for 6 weeks at the time of ingestion of $2 \mathrm{~g}$ gluten, ALV003 was reported to significantly attenuate gluteninduced intestinal mucosal injury. Importantly, no serious adverse events were reported.

Currently, a growing number of enzyme preparations claiming to aid gluten digestion are becoming commercially available, e.g. compounds containing dipeptidyl peptidase IV (DPPIV) from Aspergillus oryzae [48]. However, their effectiveness in CD patients has not been confirmed in clinical trials.

\section{Decreasing Intestinal Permeability}

Increased intestinal permeability (IP) in active CD has been measured both clinically by non-invasive sugar permeability tests (e.g. urinary lactose/mannitol (LAMA) fractional excretion ratio) [49] and by in vitro tight junction (TJ) analysis [50]. Although it is not yet finally determined whether increased IP is a primary cause or a consequence of CD, an increase of IP via opening epithelial TJs seems to be an important contributor to the influx of gluten peptides into the subepithelial adaptive immune system.

The Vibrio cholera zona occludens toxin (ZOT) is known to increase intestinal paracellular permeability by altering different TJ proteins via the $66 \mathrm{kD}$ ZOT receptor (for review see [28]). Based on the observation that the inflamed intestinal epithelium of CD patients releases a paracrine protein (zonulin) [51], which acts similar to ZOT, an octapeptide (AT-1001) corresponding to the amino acid sequence of the receptorbinding motif of human zonulin was developed. By antagonising zonulin receptor activation, AT-1001 thus protects intestinal TJ integrity.

Based on encouraging data from a phase I trial showing 
that AT-1001 (larazotide acetate) was not only well tolerated, but also decreased IP, IFN- $\gamma$ production, and intestinal symptoms following a single gluten challenge in CD patients, phase II placebo-controlled randomised trials were performed. In the study of Leffler et al. [52], 86 patients with CD in dietcontrolled remission were randomly assigned to larazotide acetate $(0.25,1,4$, or $8 \mathrm{mg}$ ) or placebo three times per day with or without gluten challenge ( $2.4 \mathrm{~g} /$ day) for 14 days. Although the primary efficacy endpoint (decrease of LAMA fractional excretion ratio) was not reached, larazotide acetate improved gluten-induced exacerbation of gastrointestinal symptom severity as measured by the Gastrointestinal Symptom Rating Scale (GSRS) at lower doses, but not at the higher dose [52]. No serious adverse events were observed. In a dose-escalation study (1.4 and $8 \mathrm{mg}$ ) in $184 \mathrm{CD}$ patients in remission who were challenged with $0.9 \mathrm{~g}$ gluten three times daily over 42 days, Kelly et al. [53] demonstrated that, compared to placebo controls, patients treated with larazotide acetate showed a significantly improved symptom score and a less pronounced anti-tTG response. However, this study also failed to demonstrate significant improvement in IP as measured by the urinary LAMA ratio.

Results from the first multicentre trial conducted in 74 sites in North America, including 342 patients, were presented as a late breaker abstract at the 2014 Digestive Disease Week (DDW) in Chicago, reporting significant symptom reduction under the $0.5 \mathrm{mg}$ dose of larazotide acetate. This study represents the largest therapeutic trial in $\mathrm{CD}$ to meet its primary endpoint of reducing signs and symptoms [54].

\section{Preventing T Cell Activation by Gluten-Derived Peptides}

\section{Blocking Deamidation of Gluten-Derived Peptides: Transglutaminase Inhibitors}

Although the deamidation of gluten by tTG may not be an absolute prerequisite for the initiation of $\mathrm{CD}$, it does at least play an important role, increasing $\mathrm{T}$ cell reactivity by improving peptide affinity to HLA-DQ2 and -DQ8 molecules. Therefore, therapeutic approaches targeting the inhibition of tTG would seem logical.

Several competitive (mainly polyamines, e.g. putrescine, spermidine, or cystamine), reversible (mainly guanosine triphosphate analogues), and irreversible (e.g. iodoacetamide, 3-halo-4.5-dihydroisoxazoles) inhibitors have been developed [55-60], which have been demonstrated in vitro to be able to attenuate the toxic effects of gliadin in epithelial cell cultures. A few have also been tested successfully ex vivo in duodenal biopsy specimens of CD patients. More recently, a group of high-affinity tTG2 inhibitors (ZED 1098, ZED 1219, and Zedira) has been developed, shown to be stable and soluble in the GI tract and not cytotoxic over a wide dosing range [47].

\section{Blocking the Binding of Deamidated Gluten Peptides to} HLA Proteins: HLA-DQ2 Inhibitors

Alternatively, blocking the binding of deamidated gluten peptides to CD-specific HLA proteins from interacting with antigen-presenting cells could also be a promising approach. A similar strategy has already been tested in other autoimmune diseases (e.g. type 1 diabetes, rheumatoid arthritis) but results in terms of clinical efficacy have been disappointing, presumably due to inadequate drug delivery. In spite of new technological advancements (e.g. use of a positional scanning nonapeptide library or silico approach) [61-64] allowing the development of ultra-high affinity peptides, in light of specific requirements regarding nontoxicity and non-immunogenicity, this approach still requires a great deal of work before reaching clinical practice.

\section{Therapy Targeted at Immune Cells}

\section{Immunosuppression by Topical Steroids}

Budesonide, a topical glucocorticoid with low systemic bioavailability mainly used in inflammatory bowel disease (IBD) affecting the distal part of the intestine, was reported to be effective also in the treatment both of RCD (e.g. non-responsive to GFD) [65, 66] and non-RCD [67]. Presumably, changing the drug formulation to target the proximal intestine should further improve its efficacy for CD.

\section{Inhibitors of T Cell Homing}

As in other T cell-mediated disease (e.g. IBD), homing of effector/memory $\mathrm{T}$ cells to the small intestine (i.e. the intestinal segment affected by $\mathrm{CD}$ ) is mainly controlled by their expression of the cell surface chemokine receptor CCR9 and the integrin $\alpha 4 \beta 7$. Antibodies targeting CCR 9 and $\alpha 4 \beta 7$ to prevent or limit $\mathrm{T}$ cell migration (homing) to the small intestine, thereby limiting local $\mathrm{T}$ cell activation, may also reduce intestinal damage and are therefore a potentially promising therapy for (refractory) CD.

Vedolizumab, a humanised anti- $\alpha 4 \beta 7$ integrin antibody, has been approved by the Food and Drug Administration (FDA) and European Medicines Agency (EMA) in 2014 as the first anti-adhesion therapy for the treatment of IBD. Phase II trials have shown that etrolizumab, a humanised monoclonal IgG1 antibody targeting $\beta 7$, is effective for the treatment of ulcerative colitis (reviewed in [68]). Currently, there are no data from CD trials.

Encouraging results for CCX282-B, a specific, orally-administered chemokine receptor CCR9 antagonist, in a clinical phase II trial in patients with Crohn's disease, have already led to the initiation of phase III clinical trials in CD [69]. Also, 
Table 1. Treatments for CD beyond the GFD (status May 2014)

\begin{tabular}{|c|c|c|c|}
\hline Underlying pathology & Therapeutic approach & Compound/organism & References \\
\hline $\begin{array}{l}\text { Immunodominant gluten } \\
\text { peptides }\end{array}$ & $\begin{array}{l}\text { wheat variants; } \\
\text { less immunogenic ancient wheat species; } \\
\text { genetically modified (gluten-depleted) } \\
\text { wheat strains with maintained baking properties; } \\
\text { gluten detoxification; } \\
\text { enzymatic cleavage of gluten fragments; } \\
\text { inactivation by polymeric binders }\end{array}$ & $\begin{array}{l}\text { prolyl endopeptidases AN-PEP; } \\
\text { oral enzyme supplementation; AVL003P } \\
\text { (HEMA-co-SS) }\end{array}$ & $\begin{array}{l}\text { preclinical } \\
\text { preclinical } \\
\text { preclinical } \\
\text { phase II clinical trial } \\
\text { phase II clinical trial } \\
\text { phase I }\end{array}$ \\
\hline Impaired mucosal barrier & $\begin{array}{l}\text { permeability inhibition; } \\
\text { zonulin/ZOT receptor blockade }\end{array}$ & AT-1001 (larazotide) & phase IIb clinical trial \\
\hline Adaptive immunity & $\begin{array}{l}\text { antigen presentation suppression; } \\
\text { inhibitors of transglutaminase; } \\
\text { blockers of HLA-DQ }\end{array}$ & ZED1227, Zedira & $\begin{array}{l}\text { phase I } \\
\text { preclinical }\end{array}$ \\
\hline Inflammatory response & $\begin{array}{l}\text { anti-TNF-alpha; } \\
\text { anti-IL-15 }\end{array}$ & $\begin{array}{l}\text { infliximab } \\
\text { AMG } 714\end{array}$ & $\begin{array}{l}\text { preclinical } \\
\text { preclinical }\end{array}$ \\
\hline $\begin{array}{l}\text { Lymphocyte recruitment } \\
\text { ('homing') }\end{array}$ & $\begin{array}{l}\text { adhesion blockade; } \\
\text { anti- } \alpha 4 \beta 7 / \text { MAdCAM-1; } \\
\text { anti-CCR9/CCL25 }\end{array}$ & $\begin{array}{l}\text { natalizumab } \\
\text { Ccx282-B, CCX025 }\end{array}$ & $\begin{array}{l}\text { preclinical } \\
\text { phase II concluded }\end{array}$ \\
\hline Immunomodulation & $\begin{array}{l}\text { gluten vaccination; } \\
\text { parasite infection }\end{array}$ & $\begin{array}{l}\text { nexvax } 2 \text { trial } \\
\text { Nectarus americanus (hookworm) }\end{array}$ & $\begin{array}{l}\text { phase IIa clinical trial } \\
\text { phase II clinical trial }\end{array}$ \\
\hline
\end{tabular}

a phase II clinical study in CD (ClinicalTrials.gov identifier: NCT00540657) has already been completed, although publishing of the results is still pending.

\section{Inhibitors of Proinflammatory Cytokines}

The central role of IL-15 in the onset and the severity of $\mathrm{CD}$ is evidenced by both animal and human data [70-74]. Based on the potent immune-modulating effects of IL-15, blockage of the IL-15 pathway either via the inhibition of IL-15 or by blocking the IL-15 receptor, or inhibition of the downstream JAK3-kinase, may be especially useful approaches for the treatment of RCD. In a phase I/II clinical trial in rheumatoid arthritis (RA), HuMax-IL15, a human monoclonal antibody targeting IL-15 (HuMax-IL15; Genmab, Copenhagen, Denmark) which blocks the epitope of IL-15 binding to the c subunit of the IL-15 receptor, was well tolerated and effected substantial improvements in disease activity [74].

Tofacitinib, an oral inhibitor of the Janus kinases 1.2 and 3 which blocks signalling involving gamma chain-containing cytokines such as IL-15, has recently been demonstrated in phase II trials to be highly effective in the treatment of RA [75] and IBD [76, 77]. These studies suggest that manipulation of the IL-15 pathway might also have therapeutic possibilities in $\mathrm{CD}$, especially for RCD and EATL, in which malignant T cell expansion is driven by IL-15. Although there are as yet no data from clinical studies in $\mathrm{CD}$, recently published results from animal studies [78] would encourage further research of this strategy.

\section{Targeting IFN- $\gamma$ and $T N F-\alpha$}

IFN- $\gamma$, produced by submucosal gliadin-sensitive $\mathrm{CD}^{+}$ $\mathrm{T}$ cells, triggers the activation of MMPs and is thus responsible for mucosal injury and villous atrophy. In addition, by increasing intestinal permeability, probably via a Rho-associated kinase-dependent pathway, it promotes the influx of gliadin peptides through the intestinal wall [79-81]. A small study using biopsies from the intestinal mucosa of patients with $\mathrm{CD}$ demonstrated that IFN- $\gamma$-blocking antibodies were able to prevent mucosal damage induced by proinflammatory cytokines released by gliadin-specific HLADQ2-restricted T lymphocyte clones [82]. However, at least in Crohn's disease, phase II clinical trials using IFN- $\gamma$ monoclonal antibodies have not shown very promising results $[83,84]$.

A more promising approach seems to be to target TNF- $\alpha$, which has been found to be more elevated in RCD [85]. The use of monoclonal antibodies against TNF- $\alpha$, which has now been the mainstay in the treatment of Crohn's disease for more than 10 years, has been described in several case reports in the treatment of RCD [86-90].

\section{CXCR3/CXCL10 Inhibitors}

CXCL10, also referred to as IFN- $\gamma$-inducible protein-10 (IP-10), is another chemokine which plays an important role in the integrin activation and migration of activated $\mathrm{T}$ cells, monocytes, and natural killer cells. Stimulation of IP-10 by the chemokine receptor 3 (CXCR3) results in the generation and recruitment of proinflammatory cells responsible for in- 
flammation and tissue destruction [91]. Recently, Lammers et al. [92] identified a novel immunomodulatory gliadin peptide that causes IL- 8 release in a chemokine receptor CXCR3-dependent manner exclusively in patients with CD, supporting the CXCR3/CXCL10 axis as a future therapeutic target for CD.

In a most recently published phase II trial by Sandborn et al. [76], BMS-936557, a human monoclonal antibody targeting CXCL10, was well tolerated and produced substantial improvements in disease activity in patients with moderately-toseverely active ulcerative colitis. To this day, clinical data from $C D$ patients are lacking.

\section{Immune Modulation and Induction of Tolerance to Gluten Peptides}

A phase Ib/IIa trial of infection with the nematode Necator americanus in patients with $\mathrm{CD}$, aiming to effect a shift from a Th1 to a Th2 milieu, has recently been reported. However, despite promising safety data, the study failed to show obvious improvement in disease activity following gluten challenge [93].

Also currently under investigation is NexVax2, a therapeutic vaccine derived from a mixture of three 15 - to 16 mer peptides aiming to generate gluten tolerance. A phase I study of NexVax2 in 40 HLA-DQ2+ CD patients, using subcutaneous doses of up to $90 \mu \mathrm{g}$ vaccine weekly for 3 weeks, showed no clinically relevant adverse events [94]. Based on these promising safety data, further trials to examine long-term efficacy are warranted.

\section{Conclusion}

Recent progress made in understanding the pathogenesis of $\mathrm{CD}$ has opened the doors for a variety of new non-dietary treatments which may be used at least as adjunctive therapy (table 1). To date, however, only a limited number of experimental therapies for CD have been assessed in phase I-II randomised, controlled clinical trials. Larazotide acetate (AT1001), which is assumed to hinder the paracellular passage of gluten through the epithelial barrier into the lamina propria by inhibiting tight junctions, has been studied in almost 100 patients to date, but an effect on hard end points, such as protection of mucosal integrity, needs to be demonstrated. Though fewer patients were studied, evidence for the efficacy of the endopeptidases contained in ALV003 which break down gluten to less or non-immunogenic peptide fragments is more obvious. Other therapies like TG2 inhibition, preventing immunogenic potentiation of gluten, or vaccination to induce tolerance to ingested gluten are less advanced but have potential for high efficacy. It should be kept in mind that most therapies discussed do not have the potential to allow the ingestion of gluten at normal daily levels of $>15 \mathrm{~g}$, but offer only an adjunctive therapy, eliminating the detrimental effects of small amounts of up to a few grams of gluten in CD patients. However, in light of the relative ease at which the obvious sources of gluten can be avoided in contrast to the many nutritional sources of hidden gluten, even a 'neutralization' of a minor amount of gluten would take most of the dietary burden from patients with CD.

\section{Disclosure Statement}

JS: No conflict of interest to declare. DS: Royalties from Eurospital, Trieste, Italy.

\section{References}

1 Ludvigsson JF, Leffler DA, Bai JC, et al: The Oslo definitions for coeliac disease and related terms Gut 2013;62:43-52.

2 Schuppan D, Zimmer KP: The diagnosis and treatment of celiac disease. Dtsch Arztebl Int 2013;110 835-846.

3 Abadie V, Sollid LM, Barreiro LB, Jabri B: Integration of genetic and immunological insights into a model of celiac disease pathogenesis. Annu Rev Immunol 2011;29:493-525.

4 Green PH: The many faces of celiac disease: clinical presentation of celiac disease in the adult population. Gastroenterology 2005;128:S74-78.

5 Green PH, Jabri B: Coeliac disease. Lancet 2003 . 362:383-391.

6 Green PH, Cellier C: Celiac disease. N Engl J Med 2007:357:1731-1743.

7 Malamut G, Afchain P, Verkarre V, et al: Presentation and long-term follow-up of refractory celiac disease: comparison of type I with type II. Gastroenterology 2009;136:81-90.
8 Malamut G, Murray JA, Cellier C: Refractory celiac disease. Gastrointest Endosc Clin N Am 2012; 22:759-772.

9 Dicke WK, Weijers HA, Van De Kamer JH: Coeliac disease. II. The presence in wheat of a factor having a deleterious effect in cases of coeliac disease. Acta Paediatr 1953;42:34-42.

10 Fasano A, Catassi C: Clinical practice. Celiac disease. N Engl J Med 2012;367:2419-2426.

11 van Overbeek FM, Uil-Dieterman IG, Mol IW, Köhler-Brands L, Heymans HS, Mulder CJ: The daily gluten intake in relatives of patients with coeliac disease compared with that of the general Dutch population. Eur J Gastroenterol Hepatol 1997;9:1097-1099.

12 Collin P, Thorell L, Kaukinen K, Maki M: The safe threshold for gluten contamination in gluten-free products. Can trace amounts be accepted in the treatment of coeliac disease? Aliment Pharmacol Ther 2004;19:1277-1283.
13 Catassi C, Fabiani E, Iacono G: A prospective, double-blind, placebo-controlled trial to establish a safe gluten threshold for patients with celiac disease. Am J Clin Nutr 2007;85:160-166.

14 Hischenhuber C, Crevel R, Jarry B, et al: Review article: safe amounts of gluten for patients with wheat allergy or coeliac disease. Aliment Pharmacol Ther 2006;23:559-575.

15 Hall NJ, Rubin GP, Charnock A: Intentional and inadvertent non-adherence in adult coeliac disease. A cross-sectional survey. Appetite 2013;68:56-62.

16 Hall NJ, Rubin G, Charnock A: Systematic review: adherence to a gluten-free diet in adult patients with coeliac disease. Aliment Pharmacol Ther 2009;30:315-330.

17 Midhagen G, Hallert C: High rate of gastrointestinal symptoms in celiac patients living on a glutenfree diet: controlled study. Am J Gastroenterol 2003;98:2023-2026. 
18 Bardella MT, Velio P, Cesana BM, et al: Coeliac disease: a histological follow-up study. Histopathology 2007;50:465-471.

19 Tuire I, Marja-Leena L, Teea S, et al: Persistent duodenal intraepithelial lymphocytosis despite a long-term strict gluten-free diet in celiac disease. Am J Gastroenterol 2012;107:1563-1569.

20 Daum S, Cellier C, Mulder CJ: Refractory coeliac disease. Best Pract Res Clin Gastroenterol 2005;19: 413-424.

21 Rubio-Tapia A, Murray JA: Classification and management of refractory coeliac disease. Gut 2010;59:547-557.

22 Hauser W, Stallmach A, Caspary WF, Stein J: Predictors of reduced health-related quality of life in adults with coeliac disease. Aliment Pharmacol Ther 2007;25:569-578.

23 Hauser W, Gold J, Stein J, Caspary WF, Stallmach A: Health-related quality of life in adult coeliac disease in Germany: results of a national survey. Eur J Gastroenterol Hepatol 2006;18:747-754.

24 Hallert C, Grant C, Grehn S, et al: Evidence of poor vitamin status in coeliac patients on a glutenfree diet for 10 years. Aliment Pharmacol Ther 2002;16:1333-1339.

25 Martin J, Geisel T, Maresch C, Krieger K, Stein J: Inadequate nutrient intake in patients with celiac disease: results from a German dietary survey. Digestion 2013;87:240-246.

26 Aziz I, Evans KE, Papageorgiou V, Sanders DS: Are patients with coeliac disease seeking alternative therapies to a gluten-free diet? J Gastrointestin Liver Dis 2011;20:27-31.

27 Wieser H: Chemistry of gluten proteins. Food Microbiol 2007;24:115-119.

28 Fasano A: Zonulin and its regulation of intestina barrier function: the biological door to inflammation, autoimmunity, and cancer. Physiol Rev 2011; 91:151-175.

-29 Schuppan D, Junker Y, Barisani D: Celiac disease: from pathogenesis to novel therapies. Gastroenterology 2009;137:1912-1933.

30 Shan L, Molberg Ø, Parrot I, et al: Structural basis for gluten intolerance in celiac sprue. Science 2002; 297:2275-2279.

-31 Qiao SW1, Bergseng E, Molberg O, Jung G, Fleckenstein B, Sollid LM: Refining the rules of gliadin $\mathrm{T}$ cell epitope binding to the disease-associated DQ2 molecule in celiac disease: importance of proline spacing and glutamine deamidation. J Immunol 2005;175:254-261.

32 Qiao SW, Bergseng E, Molberg Ø, Xia J, Fleckenstein B, Khosla C, Sollid LM: Antigen presentation to celiac lesion-derived $\mathrm{T}$ cells of a 33-mer gliadin peptide naturally formed by gastrointestinal digestion. J Immunol 2004;173:1757-1762.

33 Kagnoff MF: Celiac disease: pathogenesis of a model immunogenetic disease. J Clin Invest 2007; 117:41-49.

\34 De Re V, Caggiari L, Tabuso M, Cannizzaro R: The versatile role of gliadin peptides in celiac disease. Clin Biochem 2013;46:552-560.

-35 Kupfer SS, Jabri B: Pathophysiology of celiac disease. Gastrointest Endosc Clin N A 2012;22:639-660.

-36 Trynka G, Wijmenga C, van Heel DA: A genetic perspective on coeliac disease. Trends Mol Med 2010;16:537-550.

37 Klock C, Diraimondo TR, Khosla C: Role of transglutaminase 2 in celiac disease pathogenesis. Semin Immunopathol 2012;34:513-522.

38 Diraimondo TR, Klock C, Khosla C: Interferongamma activates transglutaminase 2 via a phosphatidylinositol-3-kinase-dependent pathway: implications for celiac sprue therapy. J Pharmacol Exp Ther 2012;341:104-114.
39 Liang L, Pinier M, Leroux JC, Subirade M: Interaction of alpha-gliadin with polyanions: design considerations for sequestrants used in supportive treatment of celiac disease. Biopolymers 2010;93: 418-428.

40 Liang L, Pinier M, Leroux JC, Subirade M: Interaction of alpha-gliadin with poly(HEMA-co-SS): structural characterization and biological implication. Biopolymers 2009;91:169-178.

41 Pinier M, Fuhrmann G, Galipeau HJ, et al: The copolymer P(HEMA-co-SS) binds gluten and reduces immune response in gluten-sensitized mice and human tissues. Gastroenterology 2012;142: 316-325.e1-12.

42 Gass J, Khosla C: Prolyl endopeptidases. Cell Mol Life Sci 2007;64:345-355.

43 Stepniak D, Spaenij-Dekking L, Mitea C, et al: Highly efficient gluten degradation with a newly identified prolyl endoprotease: implications for celiac disease. Am J Physiol Gastrointest Liver Physiol 2006;291:G621-629.

44 Edens L, Dekker P, van der Hoeven R, et al: Extracellular prolyl endoprotease from Aspergillus niger and its use in the debittering of protein hydrolysates. J Agric Food Chem 2005;53:7950-7957.

45 Tack GJ, van de Water JM, Bruins MJ, et al: Consumption of gluten with gluten-degrading enzyme by celiac patients: a pilot-study. World J Gastroenterol 2013;19:5837-5847.

46 Shan L, Marti T, Sollid LM, Gray GM, Khosla C: Comparative biochemical analysis of three bacterial prolyl endopeptidases: implications for coeliac sprue. Biochem J 2004;383:311-318.

47 Kurppa K, Hietikko M, Sulic AM, Kaukinen K, Lindfors K: Current status of drugs in development for celiac disease. Expert Opin Investig Drugs 2014;DOI: 10.1517/13543784.2014.916274.

48 Ehren J, Morón B, Martin E, Bethune MT, Gray GM, Khosla C: A food-grade enzyme preparation with modest gluten detoxification properties. PloS One 2009; 4:e6313.

49 van Elburg RM, Uil JJ, Mulder CJ, Heymans HS: Intestinal permeability in patients with coeliac disease and relatives of patients with coeliac disease. Gut 1993;34:354-357.

50 Schulzke JD, Bentzel CJ, Schulzke I, Riecken, EO, Fromm M: Epithelial tight junction structure in the jejunum of children with acute and treated celiac sprue. Pediatr Res 1998;43:435-441.

51 Drago S, El Asmar R, Di Pierro M, et al: Gliadin, zonulin and gut permeability: effects on celiac and non-celiac intestinal mucosa and intestinal cell lines. Scand J Gastroenterol 2006;41:408-419.

52 Leffler DA, Kelly CP, Abdallah HZ, et al: A randomized, double-blind study of larazotide acetate to prevent the activation of celiac disease during gluten challenge. Am J Gastroenterol 2012;107:1554-1562.

53 Kelly CP, Green PH, Murray JA, et al: Larazotide acetate in patients with coeliac disease undergoing a gluten challenge: a randomised placebo-controlled study. Aliment Pharmacol Ther 2013;37:252-262.

54 Wang C, Rasmussen H, Perrow W, et al: Larazotide acetate, a first in-class, novel tight junction regulator, meets primary endpoint and significantly reduces signs and symptoms of celiac disease in patients on a gluten-free diet: results of a multicenter, randomized, placebo controlled trial. Gastroenterology 2014;146:S-15.

55 Kapoerchan VV, Wiesner M, Overhand M, et al: Design of azidoproline containing gluten peptides to suppress CD4(+) T-cell responses associated with celiac disease. Bioorg Med Chem 2008;16:2053-2062.
6 Badarau E, Mongeot A, Collighan R, Rathbone D, Griffin M: Imidazolium-based warheads strongly influence activity of water-soluble peptidic transglutaminase inhibitors. Eur J Med Chem 2013;66: 526-530.

57 Badarau E, Collighan RJ, Griffin M: Recent advances in the development of tissue transglutaminase (TG2) inhibitors. Amino Acids 2013;44:119-127.

58 Ozaki S, Ebisui E, Hamada K, et al: Potent transglutaminase inhibitors, dithio beta-aminoethyl ketones. Bioorg Med Chem Lett 2011;21:377-379.

59 Ozaki S, Ebisui E, Hamada K, et al: Potent transglutaminase inhibitors, aryl beta-aminoethyl ketones. Bioorg Med Chem Lett 2010;20:1141-1144.

60 Watts RE, Siegel M, Khosla C: Structure-activity relationship analysis of the selective inhibition of transglutaminase 2 by dihydroisoxazoles. J Med Chem 2006;49:7493-7501.

61 Juse U, Arntzen M, Hojrup P, Fleckenstein B, Sollid LM: Assessing high affinity binding to HLADQ2.5 by a novel peptide library based approach. Bioorg Med Chemistry 2011;19:2470-2477.

62 Stepniak D, Wiesner M, de Ru AH, et al: Largescale characterization of natural ligands explains the unique gluten-binding properties of HLADQ2. J Immunol 2008;180:3268-3278.

63 Kapoerchan VV, Wiesner M, Hillaert U, et al: Design, synthesis and evaluation of high-affinity binders for the celiac disease associated HLA-DQ2 molecule. Mol Immunol 2010;47:1091-1097.

64 Juse U, van de Wal Y, Koning F, Sollid LM, Fleckenstein B: Design of new high-affinity peptide ligands for human leukocyte antigen-DQ2 using a positional scanning peptide library. Hum Immunol 2010;71:475-481.

65 Daum S, Ipczynski R, Heine B, et al: Therapy with budesonide in patients with refractory sprue. $\mathrm{Di}$ gestion 2006;73:60-68.

66 Brar P, Lee S, Lewis S, et al: Budesonide in the treatment of refractory celiac disease. Am J Gastroenterol 2007;102:2265-2269.

67 Ciacci C, Maiuri L, Russo I, et al: Efficacy of budesonide therapy in the early phase of treatment of adult coeliac disease patients with malabsorption: an in vivo/in vitro pilot study. Clin Exp Pharmacol Physiol 2009;36:1170-1176.

68 Lobaton T, Vermeire S, Van Assche G, Rutgeerts P: Review article: anti-adhesion therapies for inflammatory bowel disease. Aliment Pharmacol Ther 2014;39:579-594.

69 Keshav S, Vaňásek T, Niv Y, et al: A randomized controlled trial of the efficacy and safety of CCX282-B, an orally-administered blocker of chemokine receptor CCR9, for patients with Crohn's disease. PloS One 2013;8:e60094.

70 Malamut G, El Machhour R, Montcuquet N, et al: IL-15 triggers an antiapoptotic pathway in human intraepithelial lymphocytes that is a potential new target in celiac disease-associated inflammation and lymphomagenesis. J Clin Invest 2010;120:2131-2143.

71 Yokoyama S, Watanabe N, Sato N, et al: Antibody-mediated blockade of IL-15 reverses the autoimmune intestinal damage in transgenic mice that overexpress IL-15 in enterocytes. Proc Natl Acad Sci U S A 2009;106:15849-15854.

72 Mention JJ, Ben Ahmed M, Bègue B, et al: Interleukin 15: a key to disrupted intraepithelial lymphocyte homeostasis and lymphomagenesis in celiac disease. Gastroenterology 2003;125:730-745.

73 Maiuri L, Ciacci C, Auricchio S, et al: Interleukin 15 mediates epithelial changes in celiac disease. Gastroenterology 2000;119:996-1006. 
74 Baslund B, Tvede N, Danneskiold-Samsoe B, et al: Targeting interleukin-15 in patients with rheumatoid arthritis: a proof-of-concept study. Arthritis Rheum 2005;52:2686-2692.

75 van Vollenhoven RF1, Fleischmann R, Cohen S, et al: Tofacitinib or adalimumab versus placebo in rheumatoid arthritis. N Engl J Med 2012;367:508519.

76 Sandborn WJ, Ghosh S, Panes J, et al: A phase 2 study of tofacitinib, an oral janus kinase inhibitor, in patients with Crohn's disease. Clin Gastroen terol Hepatol 2014;DOI: 10.1016/j.cgh.2014.01.029.

77 Sandborn WJ, Ghosh S, Panes J, et al: Tofacitinib, an oral Janus kinase inhibitor, in active ulcerative colitis. N Engl J Med 2012;367:616-624.

78 Yokoyama S, Perera PY, Waldmann TA, Hiroi T, Perera LP: Tofacitinib, a janus kinase inhibitor demonstrates efficacy in an IL-15 transgenic mouse model that recapitulates pathologic manifestations of celiac disease. J Clin Immunol 2013;33:586-594.

79 Utech M, Ivanov AI, Samarin SN, et al: Mechanism of IFN-gamma-induced endocytosis of tight junction proteins: myosin II-dependent vacuolarization of the apical plasma membrane. Mol Biol Cell 2005;16:5040-5052.

80 Beaurepaire C, Smyth D, McKay DM: Interferongamma regulation of intestinal epithelial permeability. J Interferon Cytokine Res 2009;29:133-144.

81 Bethune MT, Siegel M, Howles-Banerji S, Khosla C: Interferon-gamma released by gluten-stimulated celiac disease-specific intestinal $\mathrm{T}$ cells enhances the transepithelial flux of gluten peptides. J Pharmacol Exp Ther 2009;329:657-668.
Przemioslo RT, Lundin KE, Sollid LM, Nelufer J, Ciclitira PJ: Histological changes in small bowel mucosa induced by gliadin sensitive T lymphocytes can be blocked by anti-interferon gamma antibody. Gut 1995;36:874-879.

83 Reinisch W, de Villiers W, Bene L, et al: Fontolizumab in moderate to severe Crohn's disease: a phase 2, randomized, double-blind, placebo-controlled, multiple-dose study. Inflamm Bowel Dis 2010;16:233-242.

84 Hommes DW, Mikhajlova TL, Stoinov S, et al: Fontolizumab, a humanised anti-interferon gamma antibody, demonstrates safety and clinical activity in patients with moderate to severe Crohn's disease. Gut 2006;55:1131-1137.

85 Caruso R, Marafini I, Sedda S, et al: Analysis of the cytokine profile in the duodenal mucosa of refractory coeliac disease patients. Clin Sci 2014;126: 451-458.

86 Valitutti F, Barbato M, Aloi M, et al: Autoimmune enteropathy in a 13-year-old celiac girl successfully treated with infliximab. J Clin Gastroenterol 2014; 48:264-266.

87 Turner SM, Moorghen M, Probert CS: Refractory coeliac disease: remission with infliximab and immunomodulators. Eur J Gastroenterol Hepatol 2005;17:667-669.

88 Gillett HR, Arnott ID, McIntyre M, et al: Successful infliximab treatment for steroid-refractory celiac disease: a case report. Gastroenterology 2002; 122:800-805.
89 Costantino G, della Torre A, Lo Presti MA, et al Treatment of life-threatening type I refractory coeliac disease with long-term infliximab. Dig Liver Dis 2008;40:74-77.

90 Chaudhary R, Ghosh S: Infliximab in refractory coeliac disease. Eur J Gastroenterol Hepatol 2005; 17:603-604.

91 Booth V, Keizer DW, Kamphuis MB, Clark-Lewis I, Sykes BD: The CXCR3 binding chemokine IP-10/CXCL10: structure and receptor interactions. Biochemistry 2002;41:10418-10425.

92 Lammers KM, Khandelwal S, Chaudhry F, et al Identification of a novel immunomodulatory gliadin peptide that causes interleukin- 8 release in a chemokine receptor CXCR3-dependent manner only in patients with coeliac disease. Immunology 2011;132:432-440.

93 Daveson AJ, Jones DM, Gaze S, et al: Effect of hookworm infection on wheat challenge in celiac disease - a randomised double-blinded placebo controlled trial. PloS One 2011;6:e17366.

94 Brown GJ, Daveson J, Marjason JK, et al: A phase 1 study to determine safety, tolerability and bioactivity of Nexvax2 in HLA DQ2+ volunteers with celiac disease following a long-term, strict gluten free diet. Gastroenterology 2011;140:S437-S438.

95 Kaukinen K, Lindfors K, Maki M: Advances in the treatment of coeliac disease: an immunopathogenic perspective. Nat Rev Gastroenterol Hepatol 2014; 11:36-44. 